\title{
PENYULUHAN TENTANG PEMBANGUNAN RUMAH SISTEM PANGGUNG UNTUK MENGURANGI DAMPAK AIR PASANG/BANJIR DI KOTA BANJARMASIN
}

\author{
Fathurrahman dan Abdurrahman \\ Fakultas Teknik, Prodi Teknik Sipil, Universitas Islam Kalimantan \\ E-mail :fathursipil273@gmail.com
}

\begin{abstract}
Since many years ago, house building with stage system has been known by Kalimantan society, especially the society of South Kalimantan and here the benefits of the house with stage system are introduced. In the past, the main benefit of the stage system was to avoid attack of wild animals, so the height of the house could reach $250 \mathrm{~cm}$. Beneath the house, people could do routine activities such as pounding paddy and children could play if the soil under the house was dry. In the introduction of the house benefits, it is explained that if backfilling for the house is conducted, the volume of the backfilling in the form of material, gravel, sand, and soil do not add the volume of water which comes due to tide and rain with long duration and high intensity. Volume plays important role in the increase of the overflowing water. The volume causing the increase of overflowing water can be obtained by multiplying the area of a house and its height if all house buildings do not utilize stage system. The lecture in this socialization is shown by using demonstration tool in the form of vessel which contains water, so if a solid item is put in the vessel, the surface of the water inside the vessel will rise.
\end{abstract}

Keywords: stage system, backfilling and overflowing water

\section{PENDAHULUAN}

\section{Analisis Situasi}

Menurut data geografi kota ketinggian tanah (kontur) kota Banjarmasin berada di bawah permukaan laut $\pm 70 \mathrm{~mm}$, artinya kota Banjarmasin berada di daratan rendah, banyak rawa, setiap musim hujan antara bulan Nopember sampai Maret permukaan air tanah maksimum sangat tinggi, beda tinggi permukaan air pada musim hujan dengan kemarau antara 2 m sampai 4 meter, umumnya di musim hujan curah hujan sangat tinggi puncaknya pada bulan Desember, Januari dan Februari.

Bila curah hujan dengan durasi lama dan intensitasnya tinggi diikuti oleh air pasang yang sering disebut "pasang dalam" maka terjadi luapan air di jalan-jalan pemukiman juga jalan raya dan air sampai meluap di atas ubin rumah penduduk, keadaan ini sangat mengganggu aktivitas masyarakat yang lingkungannya terjadi luapan air yang tinggi, luapan air ini walaupun jangka waktunya tidak lama sekitar 4 jam sampai 24 jam namun keadaan ini 
menyebabkan ketidaknyamanan bagi warga.

Pemerintah kota Banjarmasin untuk mengatasi atau mencegah, mengurangi luapan air ini mengeluarkan peraturan daerah (Perda) yang isinya melarang pembangunan rumah sistem urug yang maksudnya tanah dasar untuk tempat duduknya rumah diurug dengan material dari daratan tinggi, baik itu berupa tanah, sirtu, pasir atau limbah dari gergaji kayu atau material padat lainnya. Anjuran yang sifatnya mengikat ini adalah pembangunan rumah sistem panggung artinya rumah itu berdiri di atas tongkat baik berupa tongkat kayu, tongkat beton atau material konstruksi lainnya sehingga antara tanah dasar dan lantai/ubin rumah berupa ruang void (ruang kosong). Maksud Perda ini adalah bila volume air pasang di musim hujan yang maksimal sehingga terjadi luapan dengan cara tidak lagi menambah volume urugan material di sekitar rumah berarti tidak menambah volume air pasang yang maksimal tersebut. Kita contohkan segelas air yang kita masukkan benda didalamnya maka permukaan air itu akan bertambah tinggi sebesar volume benda yang dimasukkan ke dalam air dalam gelas tersebut.

Pelaksanaan Perda ini banyak mengalami hambatan terutama pada pembangunan bangunan yang permanen, masyarakat yang membangun rumah, ruko atau gedung ada yang ada yang melanggar peraturan ini karena kurangnya kesadaran warga tersebut akan perlunya menjaga keseimbangan lingkungan dengan melaksanakan pembangunan rumah, gedung, ruko sistem panggung. Untuk memberikan pengetahuan akan hal ini perlu diadakan penyuluhan kepada warga yang bermaksud ingin membangun rumah, gedung. Pengetahuan ini diberikan kepada para desain, perancang gambar bangunan yang biasanya dari awal pengurusan Izin Mendirikan Bangunan (IMB) mereka yang merancang lebih dulu.

\section{Tujuan Kegiatan}

Tujuan dari kegiatan ini untuk memberikan pengetahuan kepada masyarakat yang ingin membangun rumah agar memakai cara yang tidak berdampak kepada keseimbangan lingkungan yaitu dengan sistem panggung. 


\section{KHALAYAK SASARAN}

Sasaran yang dituju adalah para masyarakat yang membangun rumah, ketua-ketua RT, kepala desa atau lurah juga seksi Izin Mendirikan Bangunan (IMB) di kecamatan, juga tokoh masyarakat dan juga yang terkait langsung adalah desainer, arsitektur dan juru gambar yang merekalah tempat warga yang ingin membangun rumah meminta desainkan.

\section{METODE}

\section{Metode Pelaksanaan Kegiatan}

a. Mengumpulkan warga yang belum punya rumah dan akan membangun rumah, tokoh masyarakat, ketua RT, kepala desa, kelurahan, pegawai kecamatan terkait dengan pengurusan tanah dan bangunan serta desainer bangunan.

b. Memberikan penyuluhan berupa ceramah dan memberikan brosur dengan penjelasan gambar, baik cara pelaksanaan maupun gambar dampak bila melanggar peraturan daerah (Perda) tersebut.

c. Menitipkan brosur pada bagian pengawas bangunan (Wasbang) agar diberikan pada warga yang meminta formulir pengurusan IMB.

\section{PEMBAHASAN}

Rumah sistem panggung adalah rumah yang berdiri di atas tongkat penopangnya dari bahan kayu, beton atau material bahan bangunan lainnya, diantara tanah dasar di bawah rumah dengan lantai/ubin rumah berupa ruang kosong (void), bila air pasang atau terjadi hujan yang lama maka ruang kosong tersebut berisi air seperti pada Gambar 1.1 berikut.

Pada Gambar 1.1 berikut ini tampak rumah yang dibangun dengan sistem panggung, terlihat ruang kosong dibawahnya yang sebagian berisi air.
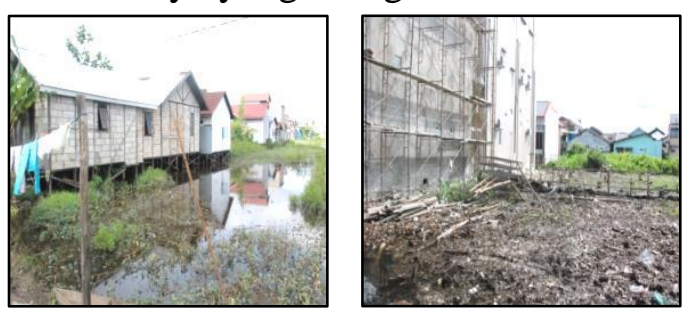

Gambar 1. Kondisi pondasi

Rumah sistem urug seperti Gambar 1. di atas berdiri di atas pondasi namun dilakukan pengurugan untuk penempatan lantainya, material urugan ini akan menambah volume air sehingga luapan air akan bertambah tinggi, volume material yang diurug tersebut tergantung dari luas rumah dan tinggi lantai bangunan dengan tanah dasar.

Dampak dari volume urugan di bawah rumah atau bangunan tersebut menambah tinggi luapan air yang 
menggenangi halaman rumah, juga jalan lingkungan dan seterusnya akan menggenangi jalan raya. Gambar 2 berikut adalah akibat dari luapan air tersebut; Gambar 1.3 luapan air menggenangi salah satu halaman rumah penduduk dan Gambar 1.4 luapan air jalan lingkungan pemukiman.
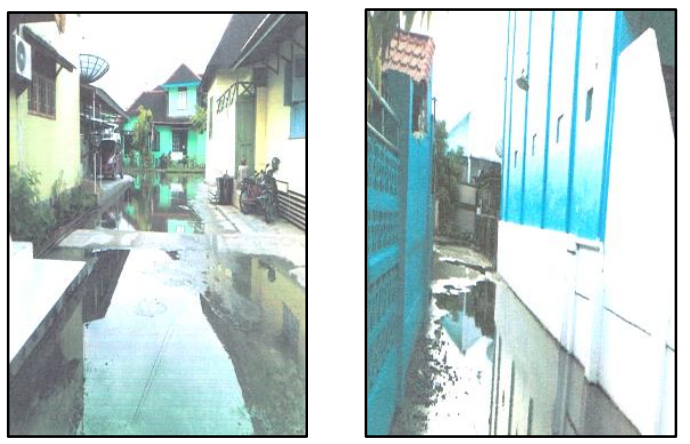

Gambar 2. Kondisi adanya luapan air

\section{KESIMPULAN}

Pelaksanaan Kegiatan Pengabdian Kepada Masyarakat ini memberikan hasil yang positif bagi masyarakat dan terlihat masyarakat secara antusias mendengarkan uraian tentang perlunya pembuatan rumah atau bangunan apapun dengan sistem panggung yang membawa dampak positif bagi lingkungan yang terbagi tiga lingkungan antara lain:

1. Lingkungan perumahan,
mengurangi, mencegah meluapnya
air pada lingkungan perumahan warga khususnya dan umumnya pada warga kota Banjarmasin.

2. Lingkungan tempat diambil/digalinya material akan mengurangi dampak buruk berupa erosi karena tanah yang terganggu akan rusak dan akan tergerus oleh air hujan.

3. Lingkungan jalan tempat armada angkutan melewatinya akan terhindar dari kerusakan karena angkutan yang membawa material akan merusak pondasi jalan karena angkutan material urugan sangat berat.

\section{DAFTAR PUSKATA}

Departemen Pendidikan dan Kebudayaan. 1999. Ilmu Pengetahuan Alam (Buku Ajar). Penerbit: Balai Pustaka.

J. Wesly.1981.Soil Mekanik. Jakarta: Lantera.

Ma'mun. 1984. Mekanika Tanah. Banjarmasin: Catatan Kuliah.

Oven ChannerHidrolik untuk Perguruan Tinggi. Jakarta: Penerbit Erlangga, 1991.

Pemerintah Kota Banjarmasin.2001. Kota Banjarmasin di Bawah Permukaan Laut. Banjarmasin: Buletin Kota.

Seminar HEDS-JICA. 1988. Seminar Pemanfaatan Semen Sebagai Konstruksi Bangunan, Jakarta: 22 Maret 1988. 
Volume 3 Nomor 1, Oktober 2017

Taufik Amir. 2002. Teori Keseimbangan Alam, Gramedia.
Zainuri. 1999. Beban-Beban Angkutan Barang yang Melintas Jalan Raya. Erlangga.

https://id.wikipedia.org/wiki/sanitasi 